\title{
O ENSINO E A CIÊNCIA NAS INSTITUIC̣̃̃̃S INACIANAS DO MUNDO LUSO DE SETECENTOS
}

\author{
Teresa Maria Rodrigues da Fonseca Rosa* \\ Instituto de Educação, Universidade de Lisboa (ULisboa), Portugal
}

RESUM0: Várias têm sido as abordagens acerca do ensino jesuítico e da sua contribuição para o atraso da cultura científica no mundo luso. Atraso que, segundo alguns autores, apenas foi ultrapassado com a Reforma Pombalina do ensino, dando a conhecer obras e autores que, havia muito, circulavam na Europa, enquanto em Portugal se prolongava a influência da Filosofia Escolástica. Essa reforma significaria a introdução das Ciências Experimentais no ensino universitário, ao lado da História Natural, nos currículos, paralelamente à importância ganha pelas matemáticas. É possível, no entanto, compreender que, na Universidade de Évora, a par de outras instituições jesuíticas, o ensino das ciências físico-matemáticas não era descurado, nem essas matérias, desconhecidas, mesmo antes da influência exercida pelos Oratorianos. O presente estudo, com base em documentos originais, visa aprofundar a percepção dos moldes em que o ensino e as ciências eram ministrados nessas instituições, contribuindo para o debate historiográfico da questão.

Palavras-chave: $\mathrm{O}$ ensino e a ciência. Instituições inacianas. Iluminismo. Oratorianos. Mundo luso.

http://dx.doi.org/10.1590/0102-4698153607

* Doutora em História da Educação pela Universidade dos Açores, Bolseira/Investigadora da FCT (Fundação para a Ciência e Tecnologia do Ministério da Educação). Pós-doutoranda em História da Educação, no Instituto de Educação da Universidade de Lisboa e Investigadora externa da UIDEF (Unidade de Investigação e Desenvolvimento para a Educação e Formação), do Instituto de Educação da Universidade de Lisboa. Investigadora/Colaboradora do GCEAP - Grupo de Pesquisa Cultura e Educação na América Portuguesa. E-mail: < teresadafons@gmail.com>. 


\section{TEACHING AND SCIENCE IN IGNACIAN INSTITUTIONS IN THE SEVEN HUNDRED'S PORTUGUESE WORLD}

ABSTRACT: Several studies have been made on the Jesuit education' contribution for the late development of a scientific culture in the lusitanian world. According to some authors, this delay was only overcome with Pombal's Reforms on Education through which authors and literary works known all over Europe were widespread in Portugal, a country dominated by the scholastic philosophy. Pombal's Reforms contributed significantly for the introduction of Experimental Sciences and Natural History in Universities' curriculums, while simultaneously there was a gain of importance of mathematical sciences. However, the facts point out that in Évora's University, as well other Jesuit's Institutions, the teaching of physics and mathematics sciences were not neglected in education, not even before Oratorian influence. This study, developed based on original documents, aims to provide an understanding on how education and science were taught in these institutions, contributing for the historical debate of this subject.

Keywords: Education and science. Ignatian institutions. Enlightenment. Oratorian. Lusitanian world.

\section{ANTECEDENTES HISTÓRICOS}

\section{A Ratio Studiorum de 1599}

A Companhia de Jesus, fundada sob a égide de Santo Inácio de Loyola e aprovada pelo Papa Paulo III, a 27 de setembro de 1540, por meio da Bula Regimini Militantis Ecclesiae, cuja formulação foi reelaborada a 21 de julho de 1550, pela Bula Exposcit Debitum de Júlio III, tinha como objetivos principais: a pregação, a prática da caridade e a educação da juventude. O ideal pedagógico dos primeiros jesuítas reflete o estilo próprio de Inácio de Loyola. A sua pedagogia nasce, sobretudo, de uma época marcada por acontecimentos profundamente relevantes que a influenciaram. Contudo, na base de todos os princípios inspiradores, esteve a fé cristã e a sua visão do mundo e da vida.

A sua originalidade não se encontra apenas numa certa forma de sensibilidade religiosa, mas sim na transformação da sua experiência pessoal numa experiência de ação pedagógica, caracterizada por uma "dimensão mística". Ela era dirigida para o serviço dos homens numa missão de apostolado, patente não só no Livro dos Exercícios Espirituais, mas também nas Constituições da Companhia de Jesus e nas diversas "ordenações de estudos", anteriores ao texto original e 
definitivo da Ratio Studiorum, de 1599. Essa pedagogia, não nascendo de um dia para o outro, foi mérito dos primeiros jesuítas dos séculos XVI a XVIII, que aproveitaram toda a riqueza cultural do Humanismo, adotando um conjunto de técnicas pedagógicas, que no tempo do seu fundador eram, sem dúvida, das mais avançadas e encontravam-se representadas no Modus Parisiensis, isto é, na metodologia educativa desenvolvida na Universidade de Paris.

Foi esse o seu ponto de partida para todo o desenvolvimento posterior, com base em experiências pedagógicas diversas que iriam ser codificadas na Ratio Studiorum de 1599, servindo de tronco educativo a todos os colégios inacianos. A Ratio continha toda uma série de "regras" autênticas, diretrizes de caráter prático, que se referiam a várias questões diferentes, tais como os aspetos de formação e distribuição de professores, os programas e os métodos de ensino. Tomada a decisão de incluir a instrução como um dos meios mais eficazes para atingir os objetivos a que a Companhia se propunha, tornou-se necessário elaborar um documento que orientasse essa atividade e que ficasse consagrada na lei fundamental: as suas "Constituições". Na parte IV, escrita em dois momentos distintos, por Inácio de Loyola, desde 1549 até à data da sua morte em 1556, encontramos o mais importante do seu pensamento sobre educação. Ela é composta por 17 pequenos capítulos e um prólogo intitulado "Como instruir nas letras e em outros meios de ajudar o próximo os que permanecem na Companbia" (ABRANCHES, 1975, p. 10). Os restantes capítulos das Constituições são dedicados às "Universidades da Companhia".

$\mathrm{Na}$ parte IV, encontramos os principais aspetos pedagógicos que estão na origem da regulamentação posterior, sendo toda dedicada à educação e formação dos jesuítas formados e em formação, e referente à orientação de caráter metodológico, revelando o interesse que Inácio de Loyola tinha pelo apostolado da educação. Podemos considerar, ainda, essa parte como o primeiro esboço da Ratio Studiorum. Como afirma Lopes (2002, p. 99) "a intenção inaciana, ao escrever estes breves dezassete capítulos [...] era a de dar uma semente para futuros documentos, especialmente a Ratio Studiorum". O legislador, ali, vai escrevendo o modo de aceitar as fundações dos colégios; o modo de se comportarem os escolásticos; os estudos que devem seguir; a organização das diversas classes e faculdades; assim como, a educação espiritual que se deve dar aos alunos.

Por outro lado, falar da Ratio Studiorum é falar de um texto fundador que permitiu o desenvolvimento de um sistema escolar de 
alcance internacional. A rede de colégios, que os jesuítas criaram em toda a Europa, constituiu efetivamente um sistema escolar dotado de um plano de estudos e regulamento próprios. Depois de muitas reformulações feitas, ao longo de meio século, o plano foi finalmente aprovado em 1599, com o título de Ratio atque Institutio Studiorum.

A primeira originalidade do programa de estudos da Ratio consistia, por um lado, no facto de se destinar simultaneamente à formação de religiosos e de leigos; por outro, no facto de incluir, além de filosofia e da teologia, o estudo sistemático das humanidades: línguas, literatura, retórica, história, teatro escolar, sendo este, certamente, o maior distintivo da proposta pedagógica da Companhia de Jesus, como refere Miranda (2009).

A Ratio foi, como o próprio nome indica, a ordenação ou sistematização dos estudos, a primeira que se fez no mundo. $\mathrm{O}$ documento não pretendeu ser um tratado pedagógico, porque os jesuítas já tinham assimilado, na própria formação religiosa, os princípios pedagógicos provenientes da experiência, da visão e dos escritos do fundador da Companhia, nomeadamente, os Exercícios Espirituais. Por isso, a Ratio tal como Gomes (1994) sublinha

[...] não é um tratado de pedagogia, mas um código, um programa, uma lei orgânica que se ocupa do conteúdo do ensino ministrado nos Colégios e Universidades da Companhia de Jesus e que se impõe métodos e regras a serem observados pelos responsáveis [...]. (GOMES, 1994, p. 143-144)

A isso, podemos acrescentar ainda as palavras de França (1952, p. 42): "A Ratio é filha da experiência, não da experiência de um homem ou de um grupo fechado, mas de uma experiência comum, viva, ampla, de tal amplitude no tempo e no espaço [...] talvez singular na história da pedagogia".

Assim, a palavra Ratio é entendida como sinónimo de "Ordo", um conjunto de regras ordenadas segundo um determinado projeto educativo. Nessa perspetiva, a Ratio mais do que um conjunto de princípios teóricos, pode ser considerada um verdadeiro sistema de ensino/ aprendizagem. Não sendo um tratado, mas um programa de "conteúdo", o Ratio adquiriu um caráter prático que possibilitava, a todos os encarregados da instrução, o caminho mais indicado para atingirem os seus objetivos.

Qualquer que fosse o curso a seguir, o programa de estudos da Ratio combinava os estudos das humanidades com os estudos científicos. Assim, se deveriam formar homens que soubessem pensar e escrever; com elevados conhecimentos de literatura, de 
história, de geografia e de artes; com um profundo entendimento de matemática, de astronomia e as restantes ciências naturais; com desenvolvido sentido crítico, apurado pela retórica e pela filosofia: homens preparados para intervir em nome do bem comum, isto é, formados numa educação que reconhece a utilidade social da retórica.

Uma sólida instrução literária era vista como um contributo indispensável para a educação do homem de bem. A todos os professores, a Ratio tornava presente que a principal finalidade dos estudos era o maior "serviço" e que todos os ensinamentos deveriam concorrer para esse fim, unir a "virtude às letras".

O Modus Parisiensis, explicitamente evocado como inspirador, refletia-se em dois aspetos fundamentais: a atividade individual e permanente do aluno, por um lado, e uma clara (e inovadora) distinção entre graus de ensino, graus de aprendizagem, assim como a ordem das matérias, da menos complexa para a mais complexa, por outro. Associados a esse método, encontravam-se também os incentivos, que se poderiam caracterizar por castigos, prémios ou louvores, ou mesmo a emulação, conhecidos como meios para encorajar o trabalho e motivar os estudantes.

A preocupação pelo método leva os autores da Ratio a prestarem, pela primeira vez, uma cuidadosa atenção à preparação dos professores, cientes de que, para favorecer o estudo das letras, era necessário favorecer os seus mestres, começando pelas próprias qualificações e assegurando as suas boas disposições e o seu compromisso pessoal na missão específica do ensino. $\mathrm{Na}$ história da educação, essa é talvez a primeira vez que se reconhece teoricamente a necessidade de preparar os professores para a sua atividade.

Focando alguns aspetos essenciais sobre o "professor", tanto a Ratio como as Constituições, e não se alargando em muitas considerações, destacam essencialmente um conjunto de regras, revelando principalmente a preocupação da sua formação. Gomes (1994, p. 148) afirma mesmo que "a Companhia de Jesus foi a primeira instituição docente que se preocupou e se ocupou com a formação pedagógica dos professores". Alguns jesuítas, como Sacchini, Jouvancy, Wagner e Kropf, compuseram manuais de didática, destinados, sobretudo, aos futuros professores da Companhia.

As Constituições preocupavam-se com o perfil dos professores e indicavam já algumas das qualidades a eles dirigidas: "quer pertençam à Companhia quer não [...] é para desejar que estes sejam sábios diligentes e dedicados ao progresso dos estudantes, tanto 
nas aulas como nos exercícios escolares"', (ABRANCHES, 1975, p. 140-141). Outros artigos acrescentam ainda: “[...] convém ao fim proposto seja cuidadosamente tratada com excelentes professores"2 (ABRANCHES, 1975, p. 158).

Esses professores deveriam interessar-se sempre pelo progresso de cada um dos alunos e pedir-lhes conta das lições, fazendo-as repetir. Levaram, também, aos que estudavam humanidades, a se exercitar, a falar habilmente latim, a fazer composições literárias e a declamá-las corretamente. Para que se atingisse esse nível ambicioso de preparação e formação dos futuros professores jesuítas, era necessário um intenso treino e apoio contínuo na sua formação, uma vez que procuravam fazer deles verdadeiros mestres dedicados à instrução. Era, pois, evidente que fossem dadas ordens ao provincial para que, na sua Província, fundasse seminários de formação de professores (ROSA, 2013).

Em síntese, a figura do professor deveria ser a de um homem sabedor, ter método e possuir as qualidades morais e pedagógicas necessárias ao elevado ministério a desempenhar. Competia-lhe ser um educador generoso, integrado com os alunos, num verdadeiro espírito familiar.

\section{Linhas gerais do currículo escolar e do método na Ratio de 1599}

$\mathrm{Na}$ Ratio vêm delineadas, em forma de breves "regras", as funções dos responsáveis do colégio a diversos níveis (provincial, reitor, prefeito dos estudos e professores); a articulação do currículo formativo; as propostas no respeitante a horários; os programas de diversas lições: os métodos educativos e didáticos. A estrutura dos curricular, estipulada na Ratio Studiorum, referia-se a três cursos. O curso de Letras, ao qual corresponde o primeiro ciclo, constituía os estudos inferiores e organizava-se do seguinte modo: o ensino do Latim, três anos de Gramática (classes ínfima, média e suprema), um ano de Humanidades e mais um de Retórica. Tinha a duração de dez anos.

A finalidade pretendida no curso de Letras era a aquisição de uma expressão oral e escrita elegante e correta, erudita, tudo, porém, em língua latina. Só poderia ser promovido à classe seguinte o aluno que tivesse atingido o grau de conhecimentos exigido. Cada classe, que era anual, tinha um professor próprio, com aulas diárias, que inicialmente eram de três horas, passando depois a duas horas e meia. Os alunos exercitavam-se diariamente na escrita e na composição, na aula e fora dela, insistindo na redação de textos, que 
deveriam ser recitados de cor. A gramática adotada era a do padre jesuíta Manuel Álvares, impressa em Portugal, em 1572, e melhorada depois pelo jesuíta António Velez, sendo utilizada até ao século XVIII (RODRIGUES, 1931). A seguir, ensinavam-se Humanidades com preleções diárias de Cícero e estudos de textos de vários autores. Do texto gramatical passava-se à exploração da poesia e da prosa de grandes autores latinos, em que se incluía o estudo da história. As aulas de Humanidades preparavam os alunos, por meio de preceitos da retórica, para a eloquência e para o domínio do vocabulário. A aula de Retórica tinha como objetivo a formação de perfeitos oradores, assim como, a preparação na arte da poesia. Nessa aula, o livro adotado era da autoria do padre jesuíta Cipriano Soares, que compôs De Arte Rhetorica Libri tres ex Aristotele, Cicerone \& Quintiliano praecipue deprompti, editado em Coimbra em 1562, reeditado em 1575 e $1583 .{ }^{3}$

O método de ensino seguido no curso de Letras exigia uma grande preparação dos professores e também um grande esforço de memória por parte dos alunos, que tinham de decorar os conteúdos estudados em cada aula para os utilizar na hora seguinte. Ao curso de Letras, seguia-se o curso de Filosofia ou Artes. A duração era de "três anos e sete meses com seis horas de aulas diárias" (MAGALHÃES, 1996, p. 16). As matérias abrangidas eram a Dialética, a Lógica, a Física e a Metafísica, sendo Aristóteles o principal autor estudado. Segundo José Martins Lopes, as matérias lecionadas dividiam-se do seguinte modo: no primeiro ano, as disciplinas de Lógica e Introdução às Ciências (o modo diverso de proceder na física e nas matemáticas), com duas horas por dia; no segundo ano, Cosmologia, Psicologia e Física, com duas horas por dia, e Matemática uma hora por dia; no último ano, a Psicologia, a Metafísica e a Filosofia Moral, com dois professores, sendo de duas horas diárias (LOPES, 2002). Esse curso visava a formação científica do aluno, por um lado, e encaminhava-se para um fim moral e religioso, por outro, tal como pretendia Inácio de Loyola (MONTEIRO, 2000).

Por último, o curso de Teologia que constituía o mais elevado grau de preparação alcançado nos colégios da Companhia: "as ciências são um meio e a teologia é o principal", escrevia Loyola nas suas Constituições (ROSA, 2013, p. 35). Tinha a duração de quatro anos: o Hebraico era estudado durante um ano, a Sagrada Escritura durante dois anos e a Teologia Moral durante dois anos. Na Teologia Escolástica, o autor seguido era São Tomás de Aquino, cuja doutrina foi considerada pela $5^{a}$ Congregação Geral, "a mais sólida segura e 
aprovada" (RODRIGUES, 1917, p. 61). O ensino da Sagrada Escritura exigia o conhecimento da língua hebraica e fazia-se uso da gramática de Francisco de Távora, impressa em Coimbra, em 1566. Para efeitos de evangelização em terras orientais, aprendiam-se também outras línguas, como o caldeu ou o árabe. E a Casuística ou Casos de Consciência era a disciplina em que se discutiam as "soluções mais convenientes para certas situações” (CARVALHO, 2011, p. 353).

\section{Breve análise do ensino científico nas aulas jesuítas}

O ensino foi uma das áreas em que mais se destacou a ação da Companhia de Jesus, entre os séculos XVI a XVIII. Os inacianos contribuíram em grande medida para o estudo, a discussão, o desenvolvimento e a difusão da ciência europeia desde o século XVI, nos seus colégios e universidades.

A atividade pedagógica da Companhia de Jesus, no que respeita ao ensino da filosofia, constituiu um dos capítulos mais importantes de toda a sua obra educativa. Os livros escolares da autoria dos jesuítas portugueses foram usados frequentemente em muitas instituições inacianas europeias, o que demonstrou a importância desses manuais como modelos orientadores do pensamento filosófico defendido pelos jesuítas.

Toda a doutrina filosófica, de raiz aristotélica, ensinada nos seus colégios, estava explanada no Curso Conimbricense, elaborado em Portugal nos fins do século XVI e princípios do século XVII. Esse curso foi programado para constituir um livro de textos a ser seguido nas suas escolas, tendo sido adotado primeiramente no Colégio das Artes em Coimbra. Os conimbricenses não se limitaram a seguir a linha "aristotélico-tomista", mas evidenciaram sinais de transição para as mudanças que, pela Europa, começavam a ser assumidas. Foram, pois, um marco importante na restauração escolástica, ocorrida nos centros escolares no início do século XVII.

O conjunto dessa obra didática, de matérias escolares, Commentarii Collegii Conimbricensis Societatis Iesu, englobava oito comentários a Aristóteles e resultou do esforço de composição dos jesuítas portugueses: Manuel de Góis; Baltazar Álvares; Sebastião do Couto; e Cosme Magalhães (CARVALHO, 2011). Com efeito, o movimento de renovação intelectual, que se fez sentir na Europa ao longo do século XVII, não deixou os inacianos insensíveis às novidades que se faziam sentir em âmbito filosófico e científico, contrárias ao sistema aristotélico. 
Se por um lado, a Companhia de Jesus não alterou a sua "filosofia pedagógica", isso não "significou que não estivessem a par das mudanças que iam ocorrendo na Europa e que não houvesse inacianos muito interessados e conhecedores dessas transformações" (MONTEIRO,2000, p. 85). A curiosidade intelectual prevaleceu, muitas vezes, mesmo face ao espírito de obediência. Era muito difícil defender a "velha filosofia" depois das descobertas de Francis Bacon (1620), Harvey (1628), Descartes (1637), Galileu (1638), Pascal (1663), Mercator (1668), Huygens (1673), Newton (1687), entre outros. E, também, depois das invenções do barómetro, termómetro, telescópio, microscópio e da máquina pneumática.

Tornara-se difícil manter a severidade de atitude perante os progressos do pensamento e da ação. Ao sistema aristotélico de cariz escolástico, cautelosamente defendido, impunha-se o movimento filosófico cartesiano, cuja origem era Descartes. Pouco a pouco, foi-se consolidando a convicção de que seria necessário simplificar e atualizar o Curso Conimbricense. Nas aulas foram dispensados certos passos dos compêndios e esclarecidos outros.

Foram vários os cursos sucessivamente redigidos por jesuítas portugueses até fim do século XVII, que vieram a substituir o dos Conimbricenses. Em todos eles, faziam-se referências à modernidade. Os mais marcantes foram a Summa Universae Philosophiae, 1642, do padre jesuíta Baltazar Teles; e o Cursus Philosophicus, 1651, de Francisco Soares, o "Lusitano". É a este jesuíta que se deve uma tentativa de atualização dos Conimbricenses, com a retificação de várias noções aristotélicas, suprimindo-se os textos no início de cada capítulo aos respetivos comentários. Na sua obra, na parte respeitante à física, serviu-se de pelo menos 120 preposições, de autores modernos, mostrando ainda estar a par dos conhecimentos de astronomia difundidos na Europa. Essa obra é considerada, por Silva Dias (1953), como uma das mais importantes que se redigiram em Portugal no século XVII.

Importa destacar também, o padre António Cordeiro com o seu Cursus Philosophicus, lecionado no Colégio das Artes, em Coimbra, de 1676 a 1680, mas que só foi impresso, em três volumes, em 1713 e 1714. É nesse autor que a objeção ao passado se manifesta com mais amplitude. Manifestou simpatia por certas ideias modernas que colheu diretamente das obras dos autores do século XVII, mostrando acompanhar o desenvolvimento científico da época (CARVALHO, 2011).

Apesar de o eixo central da formação inaciana ter sido constituído pelas humanidades e, sobretudo, pela filosofia e pela 
teologia, as ciências naturais e as matemáticas também ocuparam um lugar de destaque nos seus colégios e universidades.

Refere Carvalho (2011, p. 378) que onde a Companhia de Jesus se "mostrou mais progressista no panorama pedagógico do século séc. XVII, em Portugal, foi no ensino da Matemática".

Esse interesse no ensino das ciências ${ }^{4}$ e da matemática, em particular, remonta à fundação dos primeiros colégios da Companhia. Em 1548, Jerónimo Nadal estabeleceu o ensino da matemática no Colégio de Messina durante dois anos. O seu programa de estudos contemplava o estudo dos Elementos de Euclides, da Aritmética e da Esfera de Orôncio Fineu e, ainda, do livro de Johann Stoeffler, sobre o astrolábio.

Por outro lado, no Colégio Romano, fundado em 1551, propunha-se um curso de Filosofia de três anos, que incluía cinco semestres de matemática. Cristóvão Clávio (jesuíta alemão), um dos mais destacados astrónomos da época, criou a Academia de Matemática no colégio, desde 1581, com o objetivo de proporcionar o ensino avançado da matemática a alunos com talento para essa matéria. Foi um dos principais defensores da inserção dessa disciplina no currículo dos colégios jesuítas, como acabou por ficar estabelecido na Ratio Studiorum de 1599.

Nessa academia, estudou o jesuíta João Delgado, entre os anos 1580 e 1585. Foi o primeiro professor de matemática da aula pública da Esfera, no Colégio de Santo Antão de Lisboa. Mota (2008) sublinha ainda que a Companhia de Jesus tinha dois espaços dedicados à matemática:

\footnotetext{
Um era o Curso de filosofia, em que a disciplina é leccionada no segundo ano por um professor de filosofia ou de matemática, consoante a disponibilidade e a existência de recursos humanos. O outro é a Academia de Matemática do Colégio Romano, onde se leccionava matemática avançada e se preparam os futuros professores de matemática da Companhia. (MOTA, 2008, p. 134-135)
}

Nas Constituições redigidas por Inácio de Loiola já se previa que, nas universidades jesuítas, se lecionassem Ciências Naturais, Lógica, Física e Matemática, o que significava uma renovação ao que propunham as outras ordens religiosas. "As Artes ou as Ciências naturais dispõem os espíritos para a Teologia. [...] A lógica, a física, a metafísica e a moral, bem como as matemáticas, hão-de ser ensinadas dentro dos limites próprios do fim a que se prende" (ABRANCHES, 1975, p. 159).

Após a publicação da Ratio Studiorum garantiu-se o ensino e a difusão dessas disciplinas na maior parte dos colégios jesuítas, pois nem todos as lecionavam. Na Ratio Studiorum de 1599, podemos encontrar 
referências ao estudo da matemática nas regras do provincial. Assim,

[...] durante o segundo ano de filosofia, todos os filósofos terão uma aula de matemática de cerca de três quartos de hora. Além disso, se alguns revelarem maior aptidão e interesse por esses estudos, exercitem-se neles, depois do curso, em lições particulares. (COMPANHIA DE JESUS, 1599 citada por MIRANDA, 2009, p. 68)

Por outro lado, a Companhia de Jesus, 1599, citada por Miranda (2009, p. 136), diz que, a Ratio estabelece também nas regras do professor de filosofia, o seguinte:

[...] nela o professor incluirá [...] prolegómenos da Física, como a divisão das ciências, [os graus da] abstracção, o [conhecimento] teórico e o [conhecimento] prático, a hierarquização dos saberes, e ainda os diferentes modos de proceder da Física e da Matemática de que trata Aristóteles no livro segundo da Física.

Quanto às regras dirigidas aos professores de matemática, a Ratio acrescenta ainda segundo a Companhia de Jesus, 1599, citada por Miranda (2009, p. 146):

O professor de Matemática dará aos alunos de Física os Elementos de Euclides, durante cerca de três quartos de hora de aula. Depois dos alunos se exercitarem cerca de dois meses nesta matéria, acrescente algumas noções de geografia ou [do tratado] Da Esfera [...] todos os meses ou de dois em dois meses, procure fazer com que um dos alunos resolva algum problema conhecido de Matemática, na presença de um público alargado de filósofos e de teólogos.

Em Portugal, os jesuítas foram responsáveis pela criação de uma importante rede de instituições de ensino entre 1540 e 1759. No total dirigiram cerca de 26 colégios. Três deles foram muito importantes no ensino e na divulgação das ciências: o Colégio das Artes, em Coimbra, fundado em 1548 por D. João III, e entregue à Companhia de Jesus no ano de 1555; o Colégio de Santo Antão, em Lisboa, inaugurado em 1553; e o Colégio do Espírito Santo, em Évora, que abriu as portas ao público no mesmo ano de 1553 , passando a universidade no ano de 1559.

No Colégio de Santo Antão, funcionou desde a sua fundação até ao século XVIII a Aula da Esfera, tendo sido a mais importante instituição de ensino e prática científica do período moderno, sendo a única que assegurou ininterruptamente o ensino das ciências matemáticas até à expulsão dos jesuítas em 1759. Foi o principal centro de técnicos e especialistas na arte de navegar, da cartografia, da engenharia militar. Para além da matemática aplicada à navegação, aí se estudavam astronomia, astrologia, geometria, aritmética, arquitetura, geografia, hidrografia, ótica, assim como se construíram instrumentos científicos e máquinas simples. 
Tornou-se ponto de partida e centro de organização de alguns dos mais importantes empreendimentos científicos da época, como as expedições cartográficas ou observatórios astronómicos. O seu nome faz direta alusão ao ensino da cosmografia e introdução à astronomia, temas que, por usarem como texto o chamado Tratado da Esfera de João de Sacrobosco (obra redigida no século XIII), foram habitualmente conhecidos como assuntos de "Esfera", mas os temas que se trataram foram muito mais vastos. Acima de tudo, a Aula da Esfera foi o ponto de entrada em Portugal de muitas novidades científicas. Refere Leitão (2008, p. 20) que "nenhuma outra instituição de ensino científico foi tão internacional".

Além do Colégio de Santo Antão, em Lisboa, e da Universidade de Évora, tiveram os jesuítas aulas de matemática, por vezes públicas, em vários colégios, nomeadamente em Coimbra, no Colégio das Artes. O ensino da matemática elementar teve o seu início com Francisco Rodrigues, no Colégio de Santo Antão, ainda em 1553, mas apenas com caráter privado, ou seja, para a educação e instrução dos novos membros da Companhia de Jesus, como nos diz o padre António Franco (1726, p. 55), "Dum Ulyssipone [...] Erat is Franciscus Rodericius, que etiam Shpaeram erudite explinerat".

Além dessa aula de matemática, tinha mais o colégio aulas de latim, de língua grega, de retórica e casos de consciência:

Fueste el primero Collegio que publicamente insino em Portugal las letras de humanidade que empeçaron em ensenar los Padres Cypriano Soarez y Manuel Aluarez e el hermano Roque Sans, ator si los casos de consciência, com la Esfera que declaraua em $\mathrm{P}^{\mathrm{e}}$. Francisco Roiz [...] que oy es in la India y juntamente predicaua neste Collegio. (ARSI, Lus. n. 77, 1553-1712, f. 1- 4)

Em dezembro de 1573, o Cardeal Infante D. Henrique assumiu o papel de fundador do colégio, ao conseguir assegurar da parte do Rei D. Sebastião, seu sobrinho, uma renda anual perpétua para a Companhia de Jesus, mas impunha como condição que se lesse uma lição de matemática.

El Cardenal Iffante ha hecho instancia pera se concluir a fundacion del Collegio Santo Anton, y porque proponia condiciones muy fauorables [...] es saber que se acrescentassem las classes de latin que fuessem necessarias que seram hasta una o dos, y que se leysse una lecion de mathematica y um curso de artes de três em três anos, y com esto huã dotacion perpetua de la renta ya sabida del derecho de las especiarias. (ARSI, Lus. n. 65, 1572-1573, f. 272)

O cardeal acrescenta ainda a seguinte informação: 
[...] fique dotado e possão inteiramente cumprir as obrigações de terem doze classes de latim com as que já tem, se pollo tempo tem em diante [...] e assy hum curso de artes, e ele acabado se começara outro. Lerse ha mais no dito Collegio ordinariamente huã lição de Esphera por ser informado que he muito necessaria pera instrução dos Pilotos, e mais pessoas que costumão nauegar pera a India e outras partes. (ANTT, 1611)

O padre Jerónimo Nadal, durante a visita que efetuou à Província Portuguesa nos fins do século XVI deixou, em Coimbra, as seguintes orientações para os colégios:

Os Irmãos poderiam ouvir em Casa: [...] he muito proveitoso que os Mestres da humanidade e alguns dos estudantes mais aproveitados saibão a Esfera e alguã cousa de Cosmographia, e asi mesmo tenhão alguns extractos de cousas de moedas antíguas, e pedras preciosas e animaes e eruas e cousas semelhentes. (ANTT, 1540-1599, f. 20)

Durante o tempo em que funcionou a Aula da Esfera, houve mais de "três dezenas de professores, dos quais cerca de um terço foram estrangeiros” (LEITÃO, 2008, p. 20), muitos deles provenientes de alguns dos mais célebres colégios europeus, nomeadamente em Roma, Lovaina e Ingolstadt. Em alguns períodos críticos, ao longo do século XVII, devido ao debate epistemológico sobre o estatuto da matemática e às descobertas telescópicas de Galileu, que lançou na Europa um aceso debate, alguns desses professores foram estrangeiros. Por outro lado, por essa aula passaram também muitos outros jesuítas - cientistas europeus, em trânsito para as missões asiáticas num processo de circulação e transmissão de conhecimentos.

Com efeito, sabe-se que foi o padre João Delgado que fundou, em 1590, a aula pública da Esfera no Colégio de Santo Antão. Iniciador da tradição matemática na Província Portuguesa, onde segundo alguns autores contemporâneos, teria estudado teologia e matemática com Cristóvão Clávio, na Academia de Matemática do Colégio Romano, entre 1580 e 1585 (LEITÃO, 2008). A partir dessa data, lecionou em Coimbra, primeiro no Colégio de Jesus, um curso privado, depois no Colégio de Santo Antão (Quadro 1), atividade que manteve durante muitos anos, embora com alguns intervalos na lecionação para cumprimento das obrigações como arquiteto, cargo que tinha na Província Portuguesa jesuíta.

Como seu assistente, durante alguns anos, teve o padre Francisco da Costa, que também ensinou na Aula da Esfera e que viria a dirigir esta cadeira a partir de 1603 (Quadro 2). O padre Christoph Grienberguer assegurou essa aula, nos anos de 1601 e 1602. Logo depois, Grienberguer 
voltou para Roma, onde lecionou matemática e substituiu Clávio na cátedra de matemática do Colégio Romano, após o seu falecimento.

QUADRO 1 - Professores de matemática do século XVI

\begin{tabular}{|c|c|c|c|}
\hline \multicolumn{5}{|c|}{ Colégio de Coimbra $^{5}$} \\
\hline 1587 & João Delgado $^{6}$ & 1593 & Martim Soares \\
\hline 1590 & João Delgado & 1597 & Martim Soares \\
\hline \multicolumn{5}{|c|}{ Colégio de Santo Antão } \\
\hline $1590 / 1592$ & João Delgado & 1594 & António Leitão \\
\hline 1593 & João Delgado & 1597 & João Delgado \\
\hline \multicolumn{5}{|c|}{ Colégio de Évora/Universidade } \\
\hline
\end{tabular}

Fonte: Elaboração pelo autor deste artigo.

Outros jesuítas estrangeiros de renome garantiram a lecionação dessa cadeira durante alguns anos. Assim, podemos destacar Giovanni Paolo Lembo (1570-1618), (denominado João Paulo Lembo, na documentação portuguesa), Johann Chrysostomus Gall (1586-1643), Christoforo Borri (1583-1632), Ignace Stafford (1599-1642), Simon Fallon (1604-1642), Jan Ciermans (1602-1648), Hendrick Uwens (1618-1667), Jonh Rishton (1615-1656), Valentin Stancel (1621-1705), entre outros.

Dos jesuítas portugueses que se destacaram no ensino de matemática e na Aula da Esfera, do Colégio de Santo Antão, em Lisboa, além dos inacianos já referenciados, os padres João Delgado e Francisco da Costa, podemos destacar ainda: Luiz Gonzaga (16661747) que estudou Filosofia em Évora e Matemática, tendo lecionado esta última disciplina em Coimbra, entre 1695 e 1699, em aulas privadas, apenas destinadas a estudantes jesuítas. No ano seguinte, em Lisboa, ensinou matemática na Aula da Esfera, surgindo o seu nome nos catálogos do Arquivo Romano, no ano de 1705 (Quadro 3) a partir desta data tornou-se preceptor dos príncipes, incluindo o futuro D. João V, mantendo-se nesse cargo até 1713. A partir de 1726, volta a lecionar a Aula da Esfera.

Além desses jesuítas, podemos destacar também: João Garção (1673-1745) que lecionou na Universidade de Évora no ano de 1711 e também no ano 1720. Ensinou igualmente matemática na corte portuguesa onde foi preceptor do príncipe futuro D. João V. 
Ensinou ainda matemática em Coimbra e Santo Antão. Destacam-se também o jesuíta Jerónimo de Carvalhal, aluno de João Garção na Universidade de Évora, e o jesuíta Inácio Vieira (1678-1739), que estudou também Matemática em Évora. Nos catálogos do Arquivo Romano, aparece este como professor de matemática, no Colégio das Artes, em Coimbra, no ano de 1720. Deu, também, aulas no Colégio de Santo Antão e foi confessor do Infante D. Pedro, filho do rei D. João V. O jesuíta Manuel de Campos (1681-1758) estudou Filosofia e Matemática na Universidade de Évora, no ano de 1705 e 1706. Lecionou esta última disciplina em Évora até ao ano letivo de 1710-1711. Em Lisboa, ensinou a Aula a Esfera, aparecendo, nos catálogos do Arquivo Romano, como professor no ano de 1720 (Quadro 3). Refere Leitão (2008, p. 225) que "Manuel de Campos foi eleito membro da Academia Real de História Portuguesa e, em 1728, foi nomeado por Filipe V como professor de matemática do Colégio Real de Madrid e cosmógrafo real".

O jesuíta Diogo Soares (1684-1748), que estudou matemática em Coimbra de 1706 a 1708, onde foi aluno do padre Inácio Vieira, posteriormente lecionou essa disciplina em Coimbra entre 1714 e 1715 e mais tarde na Aula da Esfera, no Colégio de Santo Antão, em Lisboa. Nos catálogos do Arquivo Romano, surge como professor no ano de 1720, com o nome de "Diodato Soares" (Quadro 3). Em 1729, embarca para o Brasil na companhia do padre Domenico Capassi, que viera a Portugal em 1722 como o padre Giovanni Carbone, ambos matemáticos, destinados às missões. Ficaram algum tempo em Portugal, a convite do rei D. João V, como conselheiros em matéria cartográfica, onde animaram cientificamente, durante algum tempo, a Aula da Esfera no Colégio de Santo Antão, com diversas observações astronómicas. O nome de Domenico Capassi surge nos catálogos do Arquivo Romano como matemático no ano de 1726. Nesses documentos, é referido ainda que era matemático régio entre os anos de 1726 e 1748 (Quadro 3).

Importa sublinhar também o padre Eusébio da Veiga (1718 -1798), que lecionou latim em Coimbra, no Colégio das Artes, e mais tarde matemática, entre 1747 e 1749, e, tempo depois, na Aula da Esfera, no Colégio de Santo Antão em Lisboa, nos anos de 1753 a 1759. Partiu para Roma depois da extinção da Companhia de Jesus em Portugal. Dirigiu a partir de 1784 o observatório dos duques Caetani, o mais importante observatório astronómico privado. Foi eleito correspondente da Academia das Ciências de Lisboa por volta de 1789 
(LEITÃO, 2008). Por último, destacaremos o padre Inácio Monteiro, que estudou Filosofia e Matemática na Universidade de Évora, lecionou matemática no Colégio das Artes em Coimbra e publicou no ano de 1754 o Compêndio dos Elementos de Matemática. Essa obra, incluindo uma introdução à matemática e à física, surpreende pela modernidade da postura científica do seu autor.

No fim do século XVII, convencido que a Província Portuguesa tinha problemas estruturais que impediam o desenvolvimento da matemática, o Geral da Companhia de Jesus, Tirso Gonzalez, reagindo às críticas apontadas à qualidade do ensino, e principalmente à falta de missionários suficientemente preparados nessa ciência, iniciou uma reforma que se especificou em diversos documentos enviados para Portugal entre 1692 e 1702. Essa reforma de ensino foi continuada pelo Geral Miguel Ângelo Tamburini, de forma igualmente vigorosa, entre 1703 e 1711, ano em que se concluiu a reforma. Os autores dão instruções detalhas sobre o que deve ser feito e exigem a sua concretização imediata. Além disso, exigem ser periodicamente informados dos resultados da aplicação das medidas.

Um dos documentos mais importantes sobre essa reforma é aquele que o Geral Tirso Gonzalez enviou à Província Portuguesa a 12 de abril de 1692, com o título Ordenação para estimular e promover o estatuto da Matemática na Província de Portugal, e que apresenta propostas de teores diversos, em 29 pontos, a saber:

[...] não faltem nunca professores capazes nas cadeiras de Matemática dos Colégios de Lisboa, e Coimbra, e mesmo até do nosso Colégio de Évora [...] providenciem para que os professores de Filosofia não afastem os discípulos dos estudos de Matemática [...] que só sejam designados para professores de Filosofia aqueles que não desconheçam a Matemática, e os que tiverem este conhecimento sejam preferidos aos outros. [...] A Matemática [...] quer a aula teórica, quer a prática, deve durar, pelo menos, três quartos de hora [...]. Ficam obrigados a assistir regularmente às lições de Matemática [...] os estudantes filósofos do $1^{\circ}$ e do $2^{\circ}$ ano. [...] No fim de cada um dos Cursos de Filosofia de Coimbra e Évora $[. .$.$] proceda o Provincial à designação de um, dois, ou três Filósofos dos$ já licenciados, que serão incumbidos da tarefa de se dedicarem aos estudos de Matemática. (GONZALEZ, 1692 citado por ROSENDO, 1996, p. 186-192)

Ao longo do século XVII, pelo menos até a reforma de ensino do Geral da Companhia de Jesus Tirso Gonzalez, a matemática praticamente desaparece da lecionação dos colégios jesuítas em Portugal, somente se manteve com regularidade no Colégio de Santo Antão, em Lisboa. Em Coimbra, no Colégio das Artes, e na Universidade de Évora parece ter sido ministrada apenas durante 
alguns períodos. Interessante é verificar o ensino dessa cadeira de matemática nos colégios de Braga e Ilha Terceira, durante o período em que o padre António Leitão residiu nessas instituições (Quadro 2).

QUADRO 2 - Professores de matemática do século XVII

\begin{tabular}{|c|c|c|c|c|c|}
\hline \multicolumn{6}{|c|}{ Colégio de Santo Antão ${ }^{9}$} \\
\hline 1601 & Cristovão Grienberguer & 1614 & Sebastião Dias & 1665 & João Marques \\
\hline 1602 & Cristovão Grienberguer & 1615 & Manuel do Couto ${ }^{10}$ & 1669 & Georgius Gellarte \\
\hline $\begin{array}{l}1601 \\
1602\end{array}$ & $\begin{array}{c}\text { João Delgado } \\
\text { (assiste nas obras) }\end{array}$ & 1615 & Sebastião Dias ${ }^{11}$ & 1672 & Georgius Gellarte \\
\hline 1603 & Francisco da Costa & 1617 & João Paulo Lembo & 1675 & Georgius Gellarte \\
\hline 1604 & Francisco da Costa & 1619 & Francisco Machado & 1678 & Georgius Gellarte \\
\hline 1605 & Francisco Machado & 1621 & Chrisostemo Gal ${ }^{12}$ & 1681 & Georgius Gellarte \\
\hline 1606 & João Delgado & 1622 & Cristovão Gal & 1685 & Georgius Gellarte \\
\hline 1608 & João Delgado & 1623 & Chrisostemo Mogal & 1690 & Francisco Hidenofen \\
\hline 1611 & Jorge de Campos & 1625 & Chrisostemo Gal & 1693 & Georgius Gellarte \\
\hline 1612 & Sebastião Dias & 1655 & João da Costa & & \\
\hline \multicolumn{6}{|c|}{ Colégio de Braga ${ }^{13}$} \\
\hline 1603 & António Leitão & 1606 & Francisco Machado & & \\
\hline 1606 & António Leitão & & & & \\
\hline \multicolumn{6}{|c|}{ Casa Professa de São Roque ${ }^{14}$} \\
\hline & & 1603 & João Delgado & & \\
\hline & & 1614 & Francisco Machado & & \\
\hline \multicolumn{6}{|c|}{ Colégio da Ilha Terceira ${ }^{15}$} \\
\hline 1614 & António Leitão & 1622 & António Leitão & & \\
\hline 1619 & António Leitão & & & & \\
\hline \multicolumn{6}{|c|}{ Colégio de Coimbra ${ }^{16}$} \\
\hline 1606 & João Pinto do Couto & 1611 & João Pinto & 1625 & Francisco Machado \\
\hline 1606 & Diogo Seco & 1611 & João Delgado & 1649 & Joannes Riston ${ }^{17}$ \\
\hline \multicolumn{6}{|c|}{ Colégio de Évora ${ }^{18}$} \\
\hline & & 1669 & André Mendes & & \\
\hline & & 1672 & André Mendes & & \\
\hline
\end{tabular}

Fonte: Elaboração pelo autor deste artigo. 
Por outro lado, na Universidade de Évora, desde os anos de 1669, houve o ensino de Matemática, primeiro destinado só a estudantes internos e, a partir de 1700, por impulso do Geral Tirso Gonzalez, tornou-se pública. Quando a universidade atingiu o seu máximo desenvolvimento, no início do século XVIII, os professores atingiram o número de 25 em todas as cadeiras: três de Teologia Especulativa; um de Escritura Sagrada; dois de Teologia Moral ou Casos de Consciência; quatro de Filosofia ou Artes; cinco de Matemática; oito de Retórica e Latim (dois de Retórica, dois de Humanidades e quatro de Gramática); e dois de Ler e Escrever e Contar (ROSA, 2013).

Embora alguns autores façam referência apenas a uma classe de matemática, por meio da análise efetuada a vária documentação do Arquivo Romano, podemos verificar a existência, em alguns anos de lecionação, de quatro, cinco e até de sete classes (Quadro 3).

QUADRO 3 - Professores de matemática do século XVIII

\begin{tabular}{|c|c|c|c|c|c|}
\hline \multicolumn{6}{|c|}{ Colégio de Coimbra ${ }^{19}$} \\
\hline 1705 & Inácio Correia & 1749 & João de Faro & 1754 & António de Brito \\
\hline 1711 & João Mendes & 1749 & Emanuel Mendes & 1754 & António do Vale \\
\hline 1720 & Inácio Vieira & 1749 & Eusébio da Veiga & 1754 & José de Castro \\
\hline 1720 & João Mendes & 1749 & Eleutério de Souza & 1754 & João da Cunha \\
\hline \multicolumn{6}{|c|}{ Colégio do Faial ${ }^{20}$} \\
\hline & & 1700 & Cordeiro Mendes & & \\
\hline \multicolumn{6}{|c|}{ Colégio de Santo Antão ${ }^{21}$} \\
\hline 1700 & Georgius Gebarte & 1720 & Manuel de Campos & 1726 & Inácio da Costa \\
\hline 1705 & Luiz Gonzaga & 1720 & Diodato Soares & 1726 & Bernardo de Abreu \\
\hline 1717 & Georgius Gebarte & 1726 & Luiz Gonzaga & 1726 & Domenico Capassi ${ }^{22}$ \\
\hline \multicolumn{6}{|c|}{ Colégio de Évora/Universidade ${ }^{23}$} \\
\hline 1700 & Joannes Hildret & 1745 & João Pinheiro $2^{\mathrm{a}}$ Lição & 1750 & $\begin{array}{l}\text { António Couceiro } \\
\qquad 2^{\circ} \text { Ano }\end{array}$ \\
\hline 1700 & Bartolomeu Duarte & 1745 & $\begin{array}{l}\text { Jerónimo Mendes } \\
\qquad 2^{\mathrm{a}} \text { Lição }\end{array}$ & 1750 & José Leonardo \\
\hline 1711 & João Garção & 1745 & $\begin{array}{c}\text { António Tomás } 3^{\mathrm{a}} \\
\text { Liçãa }\end{array}$ & 1754 & José Godinho \\
\hline 1720 & João Garção & 1749 & Sebastião de Abreu & 1754 & Bernardino Correia \\
\hline
\end{tabular}




\begin{tabular}{|c|c|c|c|c|c|}
\hline 1720 & Domingos Pinheiro & 1749 & Francisco Gião & 1754 & Sebastião de Abreu \\
\hline 1726 & João Garção & 1749 & João de Borja & 1754 & Emanuel Mendes \\
\hline 1726 & Inácio da Silveira & 1749 & Sebastião Pimenta & 1754 & António Gomes \\
\hline 1726 & Pedro Ferreira & 1749 & Inácio de Carvalho & 1754 & José de Sá \\
\hline 1745 & $\begin{array}{l}\text { Guilherme de } \\
\text { Vasconcelos } \\
1^{\text {a Lição }}\end{array}$ & 1750 & $\begin{array}{l}\text { Francisco de Pina } 1^{0} \\
\text { Ano }\end{array}$ & 1754 & $\begin{array}{l}\text { António de } \\
\text { Vasconcelos }\end{array}$ \\
\hline 1745 & $\begin{array}{l}\text { José do Vale } \\
1^{\text {a }} \text { Lição }\end{array}$ & 1750 & António Ribeiro $2^{\circ}$ Ano & & \\
\hline
\end{tabular}

Fonte: Elaboração pelo autor deste artigo.

\section{A PROPAGAC̣ÃO DAS LUZES EM PORTUGAL}

Para Joaquina Martins (2011), falar de Luzes em Portugal implica estabelecer uma distinção entre período joanino e o período pombalino. O período joanino corresponde a um movimento aristocrático (ação dos Ericeiras) e em parte religioso (ação do Oratório), que tem, pelo menos inicialmente, a simpatia e, às vezes, o patrocínio do monarca. As Luzes pombalinas resultam de uma ascensão política e de uma ação governativa despótica que tem por objetivo uma metamorfose racional e pragmática do país.

Em Portugal, tal como em Espanha e Itália, a propagação das Luzes viu-se condicionada pela matriz católica do país, que impunha a primazia fortemente verificável da escolástica e do modelo eclesial de ensino. A dinâmica cultural seguida por D. João $\mathrm{V}$ tem sido considerada por muitos historiadores como uma das mais profícuas, na medida em que ofereceu um lugar fulcral na abertura do país ao movimento internacional do Iluminismo. Rodeado de ilustres diplomatas e políticos, como Alexandre de Gusmão ou D. Luís da Cunha, veio a reforçar a posição de Portugal em âmbito interno e externo. Refere ainda a mesma autora que,

A acção cultural de D. João V ocupa um lugar central no contexto da abertura de Portugal ao movimento internacional do Iluminismo e o papel determinante representado pelo Rei nesse processo seria justamente consagrado na designação de Luzes Joaninas. (MARTINS, 2011, p. 13) 
Nessa perspetiva, a preocupação cultural do monarca acentuouse quando enviou letrados e mesmo os "infantes" com o intuito de estagiarem nas principais capitais europeias, criando bolsas de estudo nas universidades estrangeiras, para que esses homens pudessem formarse, com vista a dar uma resposta adequada aos desafios e orientações científicas e artísticas mais recentes. Constituiu-se, dessa forma, em contributos importantes para a mudança de mentalidade do país.

Na primeira metade do século XVIII, a cultura e o ensino continuavam sob o domínio quase completo dos inacianos. Não se pode falar em completo porque existiam outras instituições religiosas que, no país, se dedicavam igualmente ao ensino, nomeadamente a Ordem dos Clérigos de São Caetano e a Congregação do Oratório de São Filipe de Néri.

A Congregação do Oratório, nascida na Itália e introduzida em Portugal por Bartolomeu de Quental e Francisco Gomes, se por um lado mantém o "espírito conservador que o ligava à escolástica", como sublinha Monteiro (2000, p. 55), por outro denota influências nítidas das novas correntes de pensamento. Essa adesão ao espírito moderno e, consequentemente, a renovação que se produziu na Congregação datam de 1737 ou 1738, pois a partir dessa altura houve uma adaptação definitiva e integral da nova filosofia.

Revelou-se como instituição preponderante e charneira na edificação de uma nova matriz cultural em Portugal, verificável no facto de ter sido aquela a primeira instituição a combater, por meio de um rejuvenescimento metodológico, o aristotelismo, em que se baseava a matriz jesuíta do conhecimento. Essa congregação atraía principalmente pela novidade que introduziu no campo humanístico, literário, científico e pedagógico. Essa pedagogia inscreveu-se na valorização das aprendizagens vernáculas.

Embora quase tão antiga como os inacianos, a Congregação do Oratório revelou-se sempre mais permeável às tendências modernas. Durante os fins do século XVII e toda a primeira parte do século XVIII, o Oratório contribuiu decisivamente para a afirmação de um novo paradigma de clérigo, em sintonia com os novos rumos da ciência. Isso acentuou cada vez mais a relevância da sua ação pedagógica, podendo salientar-se a atenção dada por D. João $\mathrm{V}$ quando estendeu aos alunos da Congregação o privilégio de entrada direta na Universidade de Coimbra, até então exclusivo aos alunos jesuítas do Colégio das Artes (SANTOS, 2010).

Foi, pois, no período joanino, que a Congregação do Oratório alcançou o auge do seu prestígio, alargando até geograficamente, com 
a autorização de abertura de um hospício, para apoio cultural em Monção, no norte de Portugal. Com esse prestígio, que se manteve com algum vigor até ao início do século XIX, viu passar, pelos bancos das suas aulas, alguns nomes de destaque como Luís António Verney, D. Manuel do Cenáculo Villas Boas e mesmo Alexandre Herculano.

Desse tempo, data também a fundação do Gabinete de Física Experimental montado na Casa das Necessidades, demonstrando bem a simpatia que D. João V sentia pela Congregação do Oratório. Revelando, assim, a importância concedida à física, por intermédio do padre Teodoro de Almeida, que elevava a física à condição de disciplina basilar do conhecimento, na linha do pensamento verneyano.

Na primeira metade do século XVIII, a cultura e o ensino continuaram sob o domínio quase completo da Companhia de Jesus. A preponderância no ensino, adquirida durante os séculos XVI e XVII, acabou por entrar em conflito com um conjunto de homens que, mediante perspetivas culturais diferentes, criticaram seus métodos pedagógicos e procuraram a mudança, quer das matérias a ensinar quer da mentalidade da "classe" dominante. Importa sublinhar que a Companhia de Jesus se manteve contrária à introdução de alterações profundas nos seus métodos pedagógicos e nas matérias lecionadas. De uma maneira geral, o ensino continuou ligado ao conceito humanista, à base de latim.

Em Portugal, os jesuítas não desconheciam nem eram alheios às novidades. A sua atitude, face a esses novos ideais e tendências, era, em meados do século XVIII, "a de simpatizantes inteligentes e de ativos colaboradores" (GOMES, 1944, p. 378). Essa opinião é partilhada também por Domingos Maurício dos Santos (1945). Para ele, o cultivo das ciências entre os inacianos estava em franco progresso desde o início do mesmo século, e esse desenvolvimento, que também se refletiu na filosofia, é anterior à publicação do Verdadeiro Método de Estudar e à influência exercida pelos Oratorianos. Não obstante, essas posições não foram partilhadas por diversos autores da corrente contrária, que defendiam que os jesuítas foram os principais responsáveis pelo atraso cultural e científico da época.

Os inacianos conheciam a Filosofia Nova e até contribuíram à sua maneira para a sua divulgação. Não podemos esquecer que os jesuítas estavam sujeitos a uma disciplina e uma organização muito rígida e severa (ROSA, 2015), e, por isso, foi muito difícil, para os que desejavam que a Ordem se reformasse e acompanhasse os novos desafios, lutar contra uma "máquina gigantesca", com uma tradição 
fortíssima. Apesar disso, se por um lado a Companhia de Jesus não alterou profundamente a sua "filosofia pedagógica" nos séculos XVII e XVIII, isso não significa que

[...] não estivessem a par das mudanças filosóficas e científicas que iam ocorrendo na Europa e que não houvesse inacianos muito interessados e conhecedores dessas transformações [...] e que não tivesse tomado consciência do real valor das suas novas propostas. (MONTEIRO, 2000, p. 85)

Na primeira metade do século XVIII, as instituições escolares da Companhia de Jesus tiveram dificuldades em obter consenso institucional para aderir, de forma célere, aos progressos científicos e filosóficos em curso.

Nos primeiros meses de 1706, a Congregação Geral da Companhia de Jesus, reunida em Roma, já tinha expresso o seu receio e a sua oposição à adesão professada por alguns mestres à filosofia de Descartes, que era considerado um dos mais importantes teóricos da ciência e da filosofia moderna. Esse órgão legislativo, o mais importante dos jesuítas, redigiu um documento com trinta preposições da doutrina cartesiana que foram julgadas como sendo perigosas; e proibidas de ser objeto de ensino nas escolas da Ordem. Pese embora, na mesma Congregação Geral, ter-se admitido que se poderiam integrar nos manuais os progressos científicos e filosóficos pertinentes e passíveis de serem aferidos como verdadeiros.

Essa preocupação institucional da Companhia, em relação aos autores modernos, não obstou a que, individualmente, alguns professores jesuítas manifestassemuma extraordinária permeabilidade e adesão às novas correntes epistemológicas e pedagógicas. Também se devem registar as tentativas, em alguns colégios da Companhia de Jesus, no sentido de se adotar os novos métodos e incutir nos seus compêndios uma atualização com os novos conhecimentos. Com efeito, alguns jesuítas em Portugal revelaram entusiasmo, abertura e apelaram para a urgência de uma renovação em alguns campos; outros resistiram a essa viragem.

O Colégio das Artes é um bom exemplo dessa hesitação e da falta de uma orientação segura no plano institucional. Se, em 1702, o referido Colégio tinha pedido a D. João V uma revisão dos seus Estatutos, já, no ano de 1740, o reitor do mesmo Colégio das Artes ordenou a fixação de um edital onde decretava a "proibição das doutrinas modernas" (FRANCO, 2006, p. 308).

Mas de facto, o movimento de renovação no campo científico, na primeira metade do século XVIII, estava a acontecer nas escolas 
inacianas. Vinha já do século anterior, a influência dos astrónomos de diversas origens, nomeadamente alemães, ingleses e italianos. No fim do século XVII, os estudos matemáticos foram reorganizados em Portugal. Posteriormente, caberia ao provincial a criação de uma especialização nessa área ${ }^{24}$ (MONTEIRO, 2000).

$\mathrm{O}$ próprio rei D. João $\mathrm{V}$ demonstrou apreço pela área científica físico-matemática, para o qual contribuiu o seu mestre de astronomia Luís Gonzaga, também jesuíta. Podemos citar mais exemplos, como a chegada de dois italianos Carbone e Capassi, ocorrida em 1722, para a sua corte, animando cientificamente o Colégio de Santo Antão, onde se realizaram diversas observações astronómicas. Foi edificado pelo monarca um observatório astronómico, onde trabalhou o padre Carbone e, posteriormente, Capassi. Muitos dos seus trabalhos acabaram por ser divulgados mais tarde nas academias de França e Inglaterra. Não foi, por isso, necessário esperar que abrisse o Gabinete da Casa das Necessidades da Congregação do Oratório no ano de 1750.

A proteção dispensada pelo monarca foi importante para que tivesse havido mais modernização científica. A filosofia manteve-se fiel à metafísica aristotélica-tomista, mas não ficou indiferente ao cartesianismo e ao experimentalismo. O curso ditado pelo jesuíta padre António Vieira, entre 1739 e 1742, é um exemplo do que se pensava da filosofia de Descartes, no Colégio de Santo Antão. Assim, também, é o curso do padre António Cordeiro, publicado em 1714, onde surgem já sinais favoráveis também à filosofia moderna. Importa sublinhar ainda, as palavras de Monteiro (2000) quando afirma:

O exemplo dado nas trinta páginas do curso do padre António Vieira prova que, em muitos Colégios da Companhia, nomeadamente no Colégio de Santo Antão, não se desconhecia o experimentalismo físico-matemático, em clara contradição com os argumentos utilizados por Luís António Verney quando acusa os inacianos de retrógrados e conservadores [...]. Por volta de 1752-1756, os Colégios jesuítas renovavam-se nos métodos e ainda nas doutrinas, já que então estas assumiram uma tonalidade caracteristicamente ecléctica, para não dizer francamente experimental. (MONTEIRO, 2000, p. 96)

Por outro lado, na última década do reinado de D. João V, assiste-se a uma acentuada perda de poder e de preponderância da Companhia de Jesus junto do monarca, o que já se verificava desde o início do seu longo reinado, em benefício da Congregação do Oratório, a qual manifestou a sua preferência e favoreceu largamente. Os Oratorianos começaram a disputar, com êxito, a visibilidade aos jesuítas nas esferas religiosas, socioestatais e culturais. 
Mas, mais importante, nesse período, seria o acentuar das controvérsias em torno da pedagogia jesuíta no quadro teóricoepistemológico e científico que suportava, dirigidas por autores de filiação intelectual iluminista. As obras que apareceram, para combater doutrinas "ineficazes", distantes das novas correntes que se iam impondo na Europa, tidas como cultas e progressivas, tiveram um papel fundamental para sedimentar a imagem tipo do jesuitismo pedagógico do país. Carvalho e Melo constituirá esses novos teóricos pedagógicos iluministas, a Congregação do Oratório e Luís António Verney, como os seus ideólogos, retirando deles os fundamentos pedagógico-científicos, para substituir e consagrar a sua pretendida viragem pedagógica, que é operada por meio de uma política sistemática de "expurgação" de toda a tradição pedagógica, científica e cultural desenvolvida em Portugal pelos mestres jesuítas.

Luís António Verney e os pedagogos do Oratório tiveram as suas críticas pedagógico-didáticas, "antijesuíticas", e os seus manuais alternativos reconhecidos e integrados como alicerces do sistema reformista pombalino dos estudos.

Neste estudo, por via da análise documental efetuada, concluímos que o ensino foi uma das áreas em que mais se destacou a ação da Companhia de Jesus, entre os séculos XVI a XVIII. Os inacianos contribuíram em grande medida para o estudo, a discussão, o desenvolvimento e a difusão da ciência europeia desde o século XVI, nos colégios e universidades.

Em Portugal, entre os fins do século XVI até meados do século XVIII, a Aula da Esfera do Colégio de Santo Antão foi a mais importante instituição de ensino e de prática científica. A matemática foi também lecionada noutros Colégios, nomeadamente no Colégio das Artes, em Coimbra e na Universidade de Évora. Por vezes, apenas como aula privada para os seus estudantes.

A Aula da Esfera foi o ponto de entrada em Portugal de muitas novidades científicas. Para ajudar a assegurar a lecionação, vieram muitos professores estrangeiros, principalmente durante $\mathrm{O}$ século XVII. No fim desse século, os estudos matemáticos foram reorganizados. Posteriormente, caberia ao Geral a criação de uma especialização nessa área (MONTEIRO, 2000).

Em meados do século XVIII, o cultivo das ciências entre os inacianos estava em franco progresso, e esse desenvolvimento, que também se refletiu na filosofia, é anterior à publicação do Verdadeiro Método de Estudar de Luís António Verney e à influência exercida pelos Oratorianos (SANTOS, 1945). 
Os jesuítas conheciam a Filosofia Nova e até contribuíram à sua maneira para a sua divulgação. Não podemos esquecer, no entanto, que os jesuítas estavam sujeitos a uma disciplina e uma organização interna muito rígida (ROSA, 2015). Com efeito, alguns jesuítas em Portugal revelaram entusiasmo, abertura e apelaram para a urgência de uma renovação em alguns campos; outros resistiram a essa viragem.

Assim, na primeira metade do século XVIII, as instituições escolares inacianas tiveram dificuldades em obter consenso institucional para aderir de forma célere aos progressos científicos em curso.

\section{REFERÊNCIAS}

ABRANCHES, J. M. As Constituições da Companhia de Jesus. Lisboa: Província Portuguesa da Companhia de Jesus, 1975.

CARVALHO, R. História do ensino em Portugal. Lisboa: Serviço de Educação, Fundação Calouste Gulbenkian, 2011.

DIAS, J. S. S. Portugal e a cultura europeia (séc. XVI a XVIII). Coimbra: Universidade de Coimbra, 1953.

FRANÇA, L. O método pedagógico dos jesuítas. Rio de Janeiro: Livraria Agir Editora, 1952. FRANCO, A. Synopsis Annalium Societatis Jesu in Lusitânia, ab anno 1540 usque ad annum 1725. Veith Joanne Herdeiros, 1726. (Impresso).

FRANCO, J. E. O mito dos jesuítas: em Portugal, no Brasil e no Oriente (séc. XVI a XX). Lisboa: Gradiva, 2006.

GOMES, J. F. O Modus Parisiensis como matriz da pedagogia dos jesuítas. Revista Portuguesa de Filosofia, Braga, v. 3, n. 50, p. 179-196, jan./set., 1994.

GOMES, J. P. Perante novos sistemas e novas descobertas. Brotéria, Lisboa, v. 39, n. 5, p. 378, nov.,1944.

LEITÃO, H. Sphaera Mundi. In: LEITÃO, H.; BERNARDO, M.; SILVA, M. Sphaera Mundi: a ciência na aula da esfera, manuscritos científicos do Colégio de Santo Antão, nas colecções da BNP. Lisboa: Biblioteca Nacional de Portugal, 2008.

LOPES, J. M. M. O projecto educativo da Companhia de Jesus: dos exercícios espirituais aos nossos dias. Braga: Universidade Católica Portuguesa, 2002.

MAGALHÃES, J. P. Um contributo para a história do processo de escolarização da sociedade portuguesa na transição do Antigo Regime. Educação, Sociedade \& Cultura, Porto, n. 5, p. 16, jan., 1996.

MARTINS, M. J. R. A educação em Portugal no século XVIII: das Luzes à Reforma Pombalina da Universidade de Coimbra. Lisboa: Faculdade de Letras da Universidade Lisboa, 2011.

MIRANDA, M. Código Pedagógico dos Jesuítas: Ratio Studiorum da Companhia de Jesus. Lisboa: Esfera do Caos, 2009.

MONTEIRO, M. C. O Padre Inácio Monteiro (1724-1812): um jesuíta português na dispersão: contribuição para a história da Companhia de Jesus durante a Época das Luzes. Lisboa: Faculdade de Letras da Universidade de Lisboa, 2000. 
MOTA, B. M. O estatuto da matemática em Portugal nos séculos XVI e XVII. Lisboa: Faculdade de Letras da Universidade de Lisboa, 2008.

RODRIGUES, F. História da Companhia de Jesus na assistência de Portugal. Porto: Livraria Apostolado da Imprensa, 1931. tomo II. II v.

RODRIGUES, F. A formação intelectual do jesuíta: leis e factos. Porto: Livraria Magalhães \& Moniz Editora, 1917.

ROSA, T. Monumenta histórica: o ensino e a Companhia de Jesus, séculos XVI a XVIII. Lisboa: Instituto de Educação da Universidade de Lisboa, 2015. p. 43-100.

ROSA, T. História da Universidade Teológica de Évora (séculos XVI a XVIII). Lisboa: Instituto de Educação da Universidade de Lisboa, 2013.

ROSENDO, A. I. R. S. Inácio Monteiro e o ensino da matemática em Portugal no século XVIII. Braga: Universidade do Minho, 1996.

SANTOS, D. M. dos. Para a história do cartesianismo entre os jesuítas portugueses do século XVIII. Revista Portuguesa de Filosofia, Lisboa, tomo I, fasc.1, p. 27-44, jan./mar. 1945.

SANTOS, E. Oratorianos. In: FRANCO, J. E.; MOURÃO, J. A.; GOMES, A. C. Dicionário histórico das Ordens e instituições afins em Portugal. Lisboa: Gradiva, 2010. p. 231-240.

\section{FONTES CONSULTADAS}

ANTT. Treslado de uma carta do Cardeal Infante D. Henrique. 1611. f. 15. Localizado em: ANTT, Lisboa. (Manuscrito). (Cartório Jesuítico, maço 56, documento 13.).

ANTT. Algumas coisas que se tem experiência aproveitarem para reger qualquer classe. 1540-1599. f. 30. Localizado em: ANTT, Lisboa. (Manuscrito). (Manuscrito da Livraria, n. 1838, f. 20.).

ARSI. Catalogus Triennales.1749-1770. f. 331. Localizado em: ARSI, Roma. (Manuscrito). (Lus. n. 49, 1749-1770, f. 13v.-14v.; f. 22v.-30v.; f. 80v.; f. 137v.; f. 147; f. 149-150.).

ARSI. Catalogus Assistentiae Lusitaniea. 1745. f. 11. Localizado em: ARSI, Roma. (Manuscrito). (Fondo Gesuitico n. 627/A-3, 1745, f. 4v.- 6.).

ARSI. Catalogus Triennales.1700-1726. f. 351. Localizado em: ARSI, Roma. (Manuscrito). (Lus. n. 47, 1700-1726, f. 26v.; f. 31; f. 68; f. 81; f. 122v.; f. 139; f. 200; f. 234; f. 242-243; f. 251v. f. 313-314; f 325-327.).

ARSI. Catalogus Triennales.1700. f. 45. Localizado em: ARSI, Roma. (Manuscrito). (Lus. n. 46 -A, 1700, f. 16; f. 33.).

ARSI. Catalogus Triennales.1678-1696. f. 407. Localizado em: ARSI, Roma. (Manuscrito). (Lus. n. 46, 1678-1696, f. 13; f. 69; f. 137; f. 210; f. 273v.; f. 406.).

ARSI. Catalogus Triennales.1649-1696. f. 487. Localizado em: ARSI, Roma. (Manuscrito). (Lus. n. 45, 1649-1696, f.11; f. 112v. f. 321; f. 366v.; f.369; f.401v.; f. 406; f. 455v.).

ARSI. Catalogus Triennales.1614-1645. f. 420. Localizado em: ARSI, Roma. (Manuscrito). (Lus. n. 44 II, 1614-1645, f. 304; f. 307v.; f. 326; f. 355v.; f. 375v.; f. 403; f. 414v.; f. 417.).

ARSI. Catalogus Triennales.1587-1611. f. 298. Localizado em: ARSI, Roma. (Manuscrito). (Lus. n. 44 I, 1587-1611, f. 10; f. 25v.; f. 38v.; f. 68; f. 75v.; f. 90v.; f. 109v.; f. 119v.; f. 134v. f. 138v.; f. 170; f. 199; f. 217v.; f. 276v.; f. 296v.).

ARSI. Catalogus Brevis .1579-1687. f. 143. Localizado em: ARSI, Roma. (Manuscrito). (Lus. n. 39, 1579-1687, f. 13; f. 35; f. 41v.; f. 54v.; f. 62v.; f. 68v.; f. 76v.; f. 86; f. 99; f. 113v.; f. 121v.; f. 128v.). 
ARSI. Epistolae Lusitaniae.1572-1573. f. 325. Localizado em: ARSI, Roma. (Manuscrito). (Lus. n. 65, 1572-1573, f. 272.).

ARSI. Epistolae Lusitaniae.1553-1712. f. 405. Localizado em: ARSI, Roma. (Manuscrito). (Lus. n. 77, 1553-1712, f. 1-4.).

\section{NOTAS}

${ }^{1}$ Constituições da Companhia de Jesus, artigo 368.

${ }^{2}$ Idem, artigo 447.

${ }^{3}$ A retórica de Cipriano Soares teve grande aceitação nas escolas jesuítas em Portugal e no exterior e foi utilizada até ao século XVIII.

${ }^{4} \mathrm{O}$ ensino das ciências abrangia áreas como mecânica, astronomia, cosmologia, geografia física, ótica, meteorologia e cosmografia, como atesta (RODRIGUES, 1917, p. 56-57).

${ }^{5}$ A.R.S.I., Lus. n. 39 Catalogus Brevis, 1579-1687, f. 13; Lus. n. 44 I Catalogus Triennales, 1587 1611,f. 10; f. 25v.; f. 75v.; f. 90v.; f. 138v. Nesse catálogo dos padres que estudavam filosofia, 16 deles estudavam também matemática (f. 13\%.).

${ }^{6}$ Neste ano de 1587, ensina matemática em casa (privado).

${ }^{7}$ A.R.S.I., Lus. n. 44 I Catalogus Triennales, 1587-1611, f. 38v.; f. 68; f. 109v.; f. 119v.

${ }^{8}$ A.R.S.I., Lus. n. 44 I Catalogus Triennales, 1587-1611, f. 134v.

${ }^{9}$ A.R.S.I., Lus. n. 39 Catalogus Brevis, 1579-1687, f. 35; f. 41v.; f. 54v.; f. 62v.; f. 68v.; f. 76v.; f. 86; f. 99; f. 113v.; f. 121v.; f. 128v.; Lus. n. 44I Catalogus Triennales, 1587-1611, f. 172; f. 199; f. 217v.; f. 276v; f. 296v.; Lus. n. 44 II Catalogus Triennales, 1614-1645, f. 307v.; f. 355v.; f. 414v.; Lus. n. 45 Catalogus Triennales 1649-1676, f. 112v.; f. 321; f. 369; f. 406; f. 455v.; Lus. n. 46 Catalogus Triennales 1678-1696, f. 13; f. 69; f. 137; f. 210; f. 273v.; f. 406.

${ }^{10} \mathrm{O}$ padre Manuel do Couto, neste ano de 1615, ensina matemática em casa (privado).

${ }^{11}$ A.R.S.I., Lus. n. 39 Catalogus Brevis, 1579-1687, f. 86. Também é lente público de matemática.

${ }^{12}$ Este padre aparece nos catálogos com o nome de Cristovão/ Chrisostemo Gal/ Mogal.

${ }^{13}$ A.R.S.I., Lus. n. 44 I Catalogus Triennales, 1587-1611, f. 192v.; f. 213v.; f. 219v.; f. 284.

${ }^{14}$ A.R.S.I., Lus. n. 44 I Catalogus Triennales, 1587-1611, f. 170; Lus. n. 44 II Catalogus Triennales, 1614-1645, f. 304. Lição de matemática em Casa (privado).

${ }^{15}$ A.R.S.I., Lus. n. 44 II Catalogus Triennales, 1614-1645, f. 326; f. 375v.; f. 403.

${ }^{16}$ A.R.S.I., Lus. n. 44 I Catalogus Triennales, 1587-1611, f. 219v.; f. 220; f. 286v.; Lus. n. 44 II Catalogus Triennales, 1614-1645, f. 417.

${ }^{17}$ A.R.S.I., Lus. n. 45 Catalogus Triennales 1649-1676, f. 11.

${ }^{18}$ A.R.S.I., Lus. n. 45 Catalogus Triennales 1649-1676, f. 366v.; f. 401v.

${ }^{19}$ A.R.S.I., Lus. n. 47 Catalogus Triennales 1700-1726, f. 68; f. 122v.; f. 234; Lus. n. 49 Catalogus Triennales $1749-1770$, f. $13 \mathrm{v} .-14 \mathrm{v}$; f. $137 \mathrm{v}$.

${ }^{20}$ A.R.S.I., Lus. n. 47 Catalogus Triennales 1700-1726, f. 31.

${ }^{21}$ A.R.S.I., Lus. n. 47 Catalogus Triennales 1700-1726, f. 26v.; f. 81; f. 200; f. 251v.; f. 325- 326v.

${ }^{22}$ Foi matemático régio, entre os anos 1726 e 1748.

${ }^{23}$ A.R.S.I., Lus. n. 46-A Catalogus Triennales 1700, f. 16; f. 33; Lus. n. 47 Catalogus Triennales 
1700-1726, f. 139; f. 242-243; f. 313- 314; f. 326v.-327; Lus. n. 49 Catalogus Triennales 17491770, f. 22v.-30v.; f. 80v.; f. 147; f. 149-150; Fondo Gesuitico n. 627/A-3 - Catalogus Assistentiae Lusitaniae, 1745, f. 4v.-6.

${ }^{24}$ Refere o padre João Pereira Gomes que "A atividade científica dos jesuítas está bem demonstrada na Aula da Esfera, aberta em Lisboa, e também nas de matemática, abertas noutros centros de ensino" (MONTEIRO, 2000, p. 64). É de sublinhar ainda que, em Évora a par da filosofia, instituiu-se, a partir de 1700, uma cadeira de Matemática (aula pública). Essa disciplina, nesse tempo, incluía, outras matérias.

Submetido: 24/08/2015

Aprovado: 08/04/2016

Contato:

Instituto de Educação da Universidade de Lisboa

Alameda da Universidade

Lisboa| Portugal

1649-013 